MAURICIO PULECIO*

Universidad de Pittsburgh (Pittsburgh, Estados Unidos)

\title{
Cuando Oliver se dio un beso con otro niño, con su mejor amigo, Dick. Lenguajes literarios y lenguajes violentos dirigidos a jóvenes LGBTQ en el sistema escolar ${ }^{* *}$
}

\section{When Oliver kissed another boy, his best friend, Dick. Literary languages and violent language directed at LGBT youth in the school system}

\section{Quando Oliver beijou outro garoto, seu melhor amigo, Dick. Linguas literárias e linguagem violenta dirigida a jovens LGBTQ no sistema escolar}

\footnotetext{
* Abogado de la Universidad Nacional de Colombia (2007), y Magíster Magna Cvm Lavde de la Pontificia Universidad Javeriana (2010), donde recibió además Mención de Honor por su trabajo de grado. Ph.D. in Hispanic Languages and Literatures con especialidad en Gender, Sexuality and Women's Studies, University of Pittsburgh. Ha recibido el Elizabeth Baranger Teaching Award 2015, por excelencia en la enseñanza, otorgado por la Graduate Student Association, Dietrich School of Arts \& Sciences, University of Pittsburgh. En 2008 fue galardonado con la beca "Jóvenes investigadores e Innovadores" conferida por COLCIENCIAS. Ha publicado varios artículos sobre temas de género, sexualidad, educación y cultura, y ha sido profesor de la Universidad Jorge Tadeo Lozano e investigador del Instituto PENSAR de la Pontificia Universidad Javeriana. Sus intereses son teorías de género y sexualidad, literatura y cultura latinoamericana, filosofía del lenguaje, filosofía política y filosofía del derecho. Correo electrónico: mauriciopulecio@yahoo.com

${ }^{* *}$ Este artículo es producto de la investigación del autor en colegios de estratos 5 y 6 en Bogotá. Una primera versión de este artículo fue presentada en la conferencia "Queering Paradigms IV" celebrada en la Universidad Federal del Estado de Río de Janeiro, Brasil, en Julio de 2012. Artículo recibido el o9/03/2015 y aceptado el 13/04/2015.
} 


\section{Resumen}

Abstract

Resumo

Este trabajo analiza la forma en que el lenguaje ofensivo mantiene y propaga la discriminación contra jóvenes LGBTQ en el sistema de educación básica. Se argumenta que este problema es global, aunque se analiza el caso colombiano para articular una respuesta desde lo local. Se muestran los resultados de un trabajo de campo realizado en colegios de estratos 5 y 6 de Bogotá, para ejemplificar las expresiones de odio que circulan en el entorno educativo. También, se estudian piezas literarias, especialmente del escritor homosexual Fernando Molano Vargas (1961-1998), y se aboga por su inclusión dentro de los currículos educativos. En conclusión, se intenta contraponer, a un lenguaje ofensivo, un lenguaje literario en el que se expresan formas de resistencia capaces de legitimar afectos no heterosexuales.

PALABRAS CLAVE:

LGBTQ | discriminación | lenguaje | literatura | educación | juventud | diversidad sexual | Fernando Molano

This paper analyzes the way in which homophobic offensive language perpetuates discrimination against LGBTQ youth in the school system. Although it exemplifies a global problem, the Colombian case articulates a local answer. Results from fieldwork conducted by the author in elite high schools in Bogotá are shown to illustrate how verbal expressions of hate permeate the educational realm. Also, some literary pieces are studied, especially those from the poet and novelist Fernando Molano Vargas (1961-1998). The inclusion of his works in educational curricula is advocated. Literary language is opposed to hate language, to express ways to resist the latter that are able to legitimate non-heterosexual affects

\section{KEYWORDS:}

LGBT | discrimination | language | literature | education | youth | sexual diversity | Fernando Molano 
Este artigo analisa como a linguagem ofensiva mantém e propaga a discriminação contra jovens LGBTQ no sistema de ensino básico. Argumenta-se que este problema é global, embora o caso colombiano seja analisado para formular uma resposta a partir do nível local. Mostram-se os resultados de um trabalho de campo realizado pelo autor em escolas de classe 5 e 6 em Bogotá, para exemplificar as expressões de ódio que circulam no contexto educacional. Peças literárias também são estudadas, principalmente do escritor homossexual Fernando Molano Vargas (1961-1998), e defende-se a sua inclusão no currículo educativo. Em conclusão, procura-se contrastar uma linguagem ofensiva com uma linguagem literária na qual formas de resistência capazes de legitimar os afetos não heterossexuais são expressas.

PALAVRAS-CHAVE:

LGBTQ| discriminação | língua | literatura | educação | diversidade sexual | Fernando Molano 


\section{Introducción}

A nivel del discurso algunas vidas no se consideran en absoluto vidas, no pueden ser humanizadas; no encajan en el marco dominante de lo humano, y su deshumanización ocurre primero en este nivel.

JUDITH BUTLER

Oh, Diego, en largas jornadas papá hizo de mí una fortaleza. Y es una maravilla como se sostienen sus muros ahora que entras en mí como un duende, y podemos a solas jugar y amarnos como dos niños

Dulce hermano de los arietes, FERNANDO MOLANO

Una fortaleza amurallada es la metáfora que nos ofrece en esta estrofa del poema "Dulce hermano de los arietes" (incluido en Todas mis cosas en tus bolsillos, 1997) el poeta bogotano Fernando Molano Vargas para expresar el acto de resistir. Dicha fortaleza, además, posibilita la construcción de un albergue espiritual en el cual hospedar a su amante masculino. Se supone que en una cultura heteronormativa los fuertes muros erigidos gracias al poder patriarcal, a los que alude Molano, deberían dotarlo de un carácter fuerte, propio del hombre heterosexual, protector de la célula familiar. Pero, en el caso del escritor, dichos muros le permiten resistir a las múltiples violencias que lo golpearon durante su vida.

Molano enfrentó miradas de reproche, exclusión familiar y discriminación institucional; eventos que impregnaron su producción literaria. Sin embargo luchó por legitimar su vida, y sus dolorosas experiencias lo inspiraron para crear piezas artísticas importantes en la literatura colombiana. Gracias al lenguaje poético, Molano construyó espacios de resistencia ética que dignificaron su vida y sus afectos, a pesar de que para principios de los años 90 eran muy pocas las opciones de sobrevivir en medio de un lenguaje contaminado de odio hacia las personas homosexuales, un lenguaje deshumanizador, como indica Butler.

El lenguaje tiene varios usos, y así como sirve para deshumanizar, también es el gran cordón umbilical al cual juristas, escritores, filósofos e intelectuales estamos atados. La disciplina jurídica, la literatura y la filosofía han construido sus discursos gracias a este recurso humano. No obstante, a pesar de su abundante producción lingüística, hasta hace poco estas áreas del conocimiento han empezado a combatir problemáticas 
como la deshumanización de personas LGBTQ. ${ }^{1}$ Una problemática con larga historia discursiva y que ha acompañado a la cultura moderna occidental desde su nacimiento.

El objetivo de este ensayo es proponer que la reflexión sobre la discriminación hacia personas LGBTQ en el sistema de educación básica exige acercamientos transdisciplinarios, capaces de integrar diversos marcos epistemológicos. La complejidad de este tipo de discriminación impide reducirla a un fenómeno netamente jurídico, cultural o político. Mi hipótesis es que las políticas "anti matoneo" no sólo deben fortalecer y educar en el lenguaje de los derechos y deberes, sino que deben integrar múltiples lenguajes que sensibilicen a la comunidad educativa y a la sociedad sobre el daño que acarrean las violencias homo-transfóbicas.

La ofensa homofóbica -como la ofensa racista- tiene efectos legales, pero también culturales, y está posibilitada por amplias estructuras de poder. Responder a una discriminación compleja implica la generación de saberes igualmente complejos que desde distintas áreas desarticulen los fuertes cimientos que sostienen los dispositivos de exclusión. No pretendo ofrecer una solución definitiva al desafío de la inclusión de jóvenes LGBTQ en el sistema escolar; más bien, mi interés es mostrar la necesidad de movilizar múltiples discursos, como el literario, para enfrentar violencias que, como la homofóbica, poseen una enorme carga lingüística. Espero mostrar la necesidad de atravesar varios marcos de conocimiento para avanzar en la investigación social en esta área, de manera que los beneficiados sean los jóvenes que, a futuro, busquen habitar el espacio escolar sin importar su género o su orientación sexual. Difundir metáforas de resistencia como las de Molano puede ayudar no sólo a dignificar la vida de personas violentadas por un sistema cultural homofóbico, sino que además ayuda a educarnos como sociedad, al conocer la historia de estas marginaciones.

El texto está compuesto por varias secciones. En las dos primeras, documento casos polémicos que ejemplifican la existencia de lenguajes de odio contra jóvenes LGBTQ y que han cobrado vidas, tanto en el contexto local como global. En la tercera formulo una hipótesis y varias preguntas que guiaron la investigación, y que aspiran a responderse teóricamente en la cuarta sección, y empíricamente en el quinto. En las secciones sexta, séptima y octava se intenta pensar la formulación de políticas de educación anti matoneo o anti bullying, a partir de la integración de varios lenguajes artísticos, especialmente el literario. El artículo conjuga varias perspectivas académicas, por lo cual construye una metodología de investigación cualitativa e interdisciplinaria que a partir

1. Utilizo la sigla LGBTQ (Lesbianas, gays, bisexuales, transgeneristas y Queer) para nombrar a personas de orientación sexual o identidad de género diversa. Sin embargo, dado que la inmensa producción de teorías Queer ha cuestionado la normalización de las identidades LGBT, utilizo la letra Q (queer) para representar también a todas las personas que se resisten a ser incluidas en los términos estrictos de la comunidad LGBT. Este debate es bastante complejo y no será abordado en este texto, aunque me interesa dejar clara la importancia del mismo. 
de la reflexión, la recolección de datos y la interpretación de teorías y trabajos previos espera conseguir sus objetivos.

\section{Diagnóstico de una realidad nacional: el matoneo a los jóvenes LGBTQ en Bogotá y Manizales}

En Abril de 2008 fue noticia el caso de dos niñas lesbianas discriminadas en un colegio de la ciudad de Manizales, en una institución que, paradójicamente, lleva el nombre de uno de los grandes humanistas del Renacimiento: Leonardo Da Vinci. Los medios de comunicación reportaron que el centro educativo, que tenía más de 1.500 estudiantes, liderados por la rectora de la Institución, gritaban “ino las queremos!” a las dos niñas, que fueron protegidas por una acción constitucional para poder continuar en las aulas tras asumir públicamente su relación sentimental (El Tiempo, 2008), (El Espectador, 2008).

A principios de septiembre de 2014, un alud de noticias, columnas de opinión, reportajes, etc., se produjo tras el lamentable suicidio del joven de 16 años Sergio Urrego, quien sufrió fuertes presiones en su colegio por manifestar una sexualidad desafiante a la norma heterosexual. Este caso fue llevado a los estrados judiciales. En primera instancia se declaró que el joven sí había sufrido discriminación por parte de las directivas de la institución educativa. Sin embargo, el caso fue apelado y conocido por el máximo Tribunal de lo Contencioso Administrativo: el Consejo de Estado. Éste revocó el fallo de primera instancia, basándose en cuestionables argumentos: que "Sergio está muerto y, por lo tanto, no hay derechos que proteger". ${ }^{2}$ A la fecha el caso sigue su curso por la vía penal y por la vía constitucional. El caso de las niñas de Manizales y el caso de Sergio Urrego son dos de los casos que más se han mediatizado en los últimos años en Colombia. Sin embargo no son los únicos, y la gravedad del caso Urrego muestra que, pese a los múltiples esfuerzos para mejorar la situación de las personas LGBTQ emprendidos por algunos Jueces, ONG, activistas, académicos, políticos, etc., la situación sigue sin mejorar.

Shoshana Felman (2002), al analizar casos muy sonados como el de O. J. Simpson, explica que este tipo de casos que generan inmensa polémica, pese a que se originan en situaciones individuales, adquieren enorme resonancia pública porque exteriorizan

2. Los medios han informado que esta fue la razón del fallo del Consejo de Estado: http://www.elespectador.com/ noticias/bogota/consejo-de-estado-revoca-fallo-reconocio-discriminacion-articulo-53O265 [28/11/2014]. En la fuente primaria, es decir, en el fallo del Consejo de Estado, se lee que el caso de Sergio: "no se trata de un hecho superado, ni de un daño consumado de los derechos ius-fundamentales, sino de la inexistencia del titular de los derechos fundamentales, pues el deceso del menor Sergio David Urrego Reyes (q.e.p.d.) acaeció antes de la formulación de la presente acción de tutela, en consecuencia un pronunciamiento de fondo sobre el amparo reclamado de los derechos [...] resultaría inocuo pues ya no hay materia para resolver” (Folios 44-45. Cursivas mías). 
traumas sociales inconscientes, que difícilmente pueden expresarse en la vida cotidiana. Por eso en la resolución del caso se intenta obtener una respuesta racional a una violencia encriptada, más amplia y arraigada. Dice Felman "these trials staged paroxistic spectacles both of the drama of the law and of the drama of culture". La repercusion social del caso de Sergio escenifica no sólo su drama, sino el de muchos otros jóvenes LGBTQ, y simboliza la existencia de un profundo abismo cultural que separa a la sociedad heteronormativa de los sectores sexualmente diversos.

Los jóvenes LGBTQ aún son extremadamente vulnerables en los espacios escolares. Por ello, aunque las discusiones académicas sobre sexualidad son cada vez más novedosas, hoy día un adolescente violentado difícilmente cuenta con la capacidad de oponerse al poder que ostentan los discursos de odio. Ni siquiera Sergio Urrego, pese a su inteligencia y capacidad de reflexión, pudo seguir enfrentando el acoso institucional.

\section{Más allá de Colombia: diagnóstico de un problema global}

Temas como el matrimonio y la adopción de personas del mismo sexo se discuten a menudo en instancias legales de muchos países de occidente. Estas discusiones son reportadas en espacios de consumo cultural masivo, como programas de televisión, periódicos y revistas, y se difunden con rapidez gracias a Internet. Sin embargo, pareciera que sólo el eco de esas discusiones llega a los colegios, y los estudiantes y directivos casi siempre desinformados sienten miedo de abordar estos debates. En el Estado de Nueva York, por ejemplo, dos meses después de aprobarse el matrimonio entre parejas del mismo sexo, el 18 de Septiembre de 2011 se suicidó el joven de catorce años Jamey Rodemeyer, quien también sufrió enorme acoso escolar, y cuyo testimonio y llamado a la resistencia quedó colgado en Youtube. ${ }^{3}$ Este caso nos indica que la situación de estudiantes LGBTQ discriminados es un desafío transnacional. Por ello, aunque las violaciones de derechos fundamentales de los estudiantes LGBTQ demanden respuestas locales inmediatas, cualquier acción que busque mejorar sus vidas puede tener impacto global.

Como vemos, a nivel mundial hay una enorme brecha que separa el avance legal y académico de la realidad violenta que enfrentan las personas sexualmente diversas en el sistema escolar. En Colombia, el caso de Sergio hace presente esa realidad, y nos enfrenta a la urgente necesidad de cuestionar los paradigmas culturales juveniles, y no sólo luchar por obtener cambios en la legislación. 
Considero importante cultivar intentos para avanzar, de forma simultánea, tanto en el campo cultural como en el campo legal, a pesar de que el fetichismo legal ${ }^{4}$ que caracteriza nuestra cultura legalista nos haga confiar excesivamente en el derecho como única forma de reivindicar la validez de nuestra existencia. También, a pesar de que muchas veces las reflexiones sobre la transformación del campo cultural prescindan de profundizar sus relaciones con el sistema jurídico y político. Por esto, es muy importante reconocer la interdependencia que existe entre los cambios legales y los cambios culturales, y en esa medida la generación de discursos transdisciplinarios resulta de más provecho que las miradas monodiscursivas.

Quisiera además pensar esta discusión no sólo como una forma de proteger a los estudiantes LGBTQ en escuelas que los convierten en víctimas. En el fondo, lo fundamental es humanizar el sistema escolar para que sea un espacio capaz de desmantelar las múltiples violencias que lo atraviesan, en vez de reproducirlas.

\section{Enunciación de una hipótesis}

Es importante preguntarnos: ¿qué hubiera pasado si los compañeros y profesores de Sergio hubieran conocido un poco más de la literatura colombiana? Quizá hubieran descubierto la cantidad de renombrados escritores homosexuales que han aportado a nuestra historia cultural. ¿Qué hubiera pasado si en las clases de historia no solamente se enseñara a los jóvenes que nuestra historia ha sido forjada gracias a las ideas de intelectuales heterosexuales, sino además que gracias a sensibilidades homosexuales como las de Porfirio Barba Jacob, José María Vargas Vila o Raúl Gómez Jattin nuestra literatura se ha posicionado en la producción literaria en lengua castellana?

$¿$ Es posible pensar qué los estudiantes lean a escritores como Fernando Molano Vargas o a Marvel Moreno, que pueden enseñarles a pensar desde otras aceras y a generar empatía con las vidas que existen fuera de las normas masculinas? Comparto estas preguntas para reflexionar si casos tan tristes como el de Sergio quizá se hubieran podido evitar si se educara bajo horizontes más amplios y reconocedores de la diversidad humana.

\footnotetext{
4. Por medio del concepto "fetichismo legal" Julieta Lemaitre (2009) explica el excesivo apego que se ha tenido, históricamente, hacia la norma, lo cual ha generado críticas al derecho (desde los teóricos marxistas del derecho, como también de parte de los formalistas) en tanto que herramienta primordial de resolución de los conflictos sociales (El derecho como conjuro 383-389). Sin embargo, Lemaitre también explica que el "fetichismo legal” tiene una dimensión esperanzadora, pues sus victorias tienen gran valor emocional, transmiten esperanza, y generan impactos culturales trascendentales para el mejoramiento de las condiciones de vida de muchas comunidades violentadas. En este último punto concuerdo con la profesora Lemaitre, aunque mi interés esté puesto en fortalecer el cambio cultural y examinar su posible impacto en el cambio legal, no al contrario.
} 
En el universo literario es posible encontrar miles de piezas poéticas que contribuirían a derribar los prejuicios que una parte de la humanidad ha construido contra las personas homosexuales. Como he indicado, la discriminación no es únicamente un problema legal, también es un problema cultural, y puede empezar a contrarrestarse a partir de fuentes escritas o visuales menos politizadas, como las piezas literarias o cinematográficas.

No se trata de jerarquizar los saberes, y afirmar que la literatura, la historia o incluso el cine son "verdaderas" herramientas para avanzar en modelos de educación incluyente y en la erradicación de prejuicios. Tampoco se trata de afirmar que la literatura o el cine son la nueva tabla de salvación de las personas LGBTQ. Pero es importante reconocer que para avanzar en esta discusión debemos trabajar desde múltiples disciplinas, utilizando más recursos como el literario o el cinematográfico, evitando al máximo recorrer los tortuosos caminos jurídicos. Las humanidades tienen un potencial inmenso para la transformación cultural, y el establecimiento de puentes entre la creación artística y los avances legales es vital para combatir la violencia contra las personas LGBTQ en la escuela. Desmantelar la discriminación en la escuela nos convierte en migrantes éticos: nos invita a movernos entre el terreno de los derechos y los amplios territorios de las artes y las humanidades.

\section{La performatividad de la ofensa}

El insulto [...] asume su proporción específica en el tiempo. Ser insultado es una de las primeras formas de agravio lingüístico que uno aprende

JUDITH BUTLER

En la frase anterior Butler intenta revelar la capacidad del lenguaje para esconder los mecanismos de poder ínsitos a la historia de las ofensas. Las ofensas se repiten en el tiempo, y en cada enunciación la palabra insultante va creando, a partir de su reinstauración, la realidad peyorativa del que es nombrado. Que el lenguaje es performativo significa que crea realidades a medida que se repite, y que su capacidad creadora perfora la identidad del que es interpelado por la palabra hiriente.

Didier Eribon afirma que "un gay o una lesbiana es una persona que, en un momento u otro de su vida, ha sido o sabe que puede ser insultado" (2000: 63). Las palabras de Eribon nos enseñan que las poblaciones LGBTQ son lingüísticamente vulnerables, y dicha vulnerabilidad se explica por la pesada carga de odio que han adquirido las palabras que les nombra. 
¿De qué formas son nombrados los jóvenes LGBTQ en el mundo escolar? Es importante reiterar constantemente esta pregunta. En la repetición se esconde una estrategia subversiva que, utilizando el mismo mecanismo performativo que el lenguaje de odio ha seguido para empoderar sus frases hirientes, cuestiona el dañino mecanismo operatorio de las palabras que nombran a las sexualidades no heterosexuales en las escuelas. También, la repetición es una llamada a la acción dirigida a docentes y jóvenes LGBTQ, para que desde la reiteración de su existencia, puedan reescribir su realidad con argumentos sólidos, descontaminados de odio y marginación.

\section{Lenguajes de odio, lenguajes repetitivos en la realidad}

Para esta parte del trabajo se realizó un trabajo de campo, siguiendo una metodología de investigación cualitativa. Se diseñaron e implementaron entrevistas semi dirigidas para la recolección de datos en dos oportunidades, en el año 2009 y en el año 2012.5 Los participantes fueron estudiantes de grados $6^{\circ}$ a $11^{\circ}$ de tres colegios católicos y privados: uno mixto, uno masculino y uno femenino, de los estratos sociales más "altos"6 de Bogotá $(4,5$ y 6).7 Se seleccionó una muestra representativa de estudiantes -10 estudiantes de grupos de 30, y 15 de un grupo de 40-. En estas entrevistas el objetivo fue explorar el lenguaje que los jóvenes utilizan para nombrar a sus compañeros LGBTQ. Presento algunas respuestas que obtuve, y que ejemplifican el lenguaje ofensivo que circula en la escuela.

¿Qué ha visto que los otros estudiantes le hayan dicho o hecho a su compañero por su orientación sexual?:8

"[...] que es un marica, que nunca va a triunfar por ser gay, que es cacorro, que es un bobo que se deja penetrar por otros hombres, lo rechazan porque le tienen asco" (Estudiante de 12 años de edad).

5. Con esta distancia temporal corroboré también la persistencia del fenómeno social.

6. La estratificación que generan las desigualdades sociales en Colombia se refleja también, desafortunadamente, en esta forma de clasificar los colegios.

7. Aclaro que esta pequeña muestra vendría, en cierta forma, a complementar importantes estudios como Homofobia y Convivencia en la Escuela de Erik Cantor (2008). Este realiza un amplio trabajo de campo para documentar y analizar la discriminación verbal y física que afrontan estudiantes LGBTQ en colegios públicos de estratos "bajos" de Bogotá. El presente trabajo, con base en la información aquí presentada, mostraría que la situación en los colegios de estratos "altos" no difiere de la de los "estratos" bajos, y por ello podemos afirmar que la violencia contra jóvenes LGBTQ es un problema estructural del sistema de educación básica colombiano.

8. En las entrevistas, al preguntar se aclaró que, aunque la orientación sexual hace parte de la esfera íntima de la persona, tiene repercusiones públicas, sobre todo cuando nos referimos a compañeros de clase "percibidos" como LGBTQ. 
"He visto que le dicen loca, maricón h.p., homosexual, gay iqué gonorrea que le gusten los hombres! ... y le pegan, le quitan las cosas y no lo dejan en los grupos de trabajo” (Estudiante de 15 años de edad).

"Le dicen que es gay, que hay que mantenerse apartado de él" (Estudiante de 16 años de edad).

"Se la tienen al rojo y nunca lo dejan en paz ya que se la pasan insultándolo" (Estudiante de 16 años de edad).

¿Qué ha visto que un profesor, directivo o empleado del colegio le haya dicho o hecho a su compañero/compañera por su orientación sexual homosexual, bisexual o transgenerista? 9

“(...) un profesor de educación física le dijo que tenía que jugar fútbol para que dejara de ser afeminado, y que no le tuviera miedo al balón” (Estudiante de 18 años de edad).

"Lo hacen quedar mal frente a los compañeros, lo chiflan y hacen chistes de maricas, en especial el profesor de inglés" (Estudiante de 13 años de edad).

"Le dijo que parecía una lesbiana y que si seguía en esa tónica se saliera de la clase" (Estudiante de 13 años de edad).

"Que le pegue duro a la pelota de Voleibol... y sino todos los chiflan porque se rompería como una galleta.... ¡Rómpete Galleta! ${ }^{10} . .$. esa es la frase con la que el profesor lo invitaba a uno a practicar este deporte" (Estudiante de 14 años de edad).

Aparte de los destinatarios ¿a quién afectan estas expresiones? ¿Hay reproche social hacia el lenguaje peyorativo, que todos los que hemos pasado por el sistema escolar hemos oído dirigir contra personas LGBTQ? Al respecto es fundamental traer nuevamente las palabras de Eribon:

Desde que descubro que tal o cual injuria que he oído aprendiendo en el lenguaje se dirige a mí, que es de mí de quien se habla, las palabras de estigmatización hacen entrar dentro de mí el sentimiento de la vergüenza, del miedo, de la inferioridad social que me atribuye y que llega a ser la misma definición de mi personalidad (Eribon, 2000: 56-57).

Eribon habla desde el sujeto violentado; esta violencia está soportada en el entorno educativo dada su organización jerárquica. En el sistema de educación la situación de habla privilegiada del docente hace que, entonces, interrogar el lenguaje ofensivo sea toda una proeza. La cultura escolar ha acogido estas expresiones, y circulan repetitiva-

9. Fue necesario explicar a varios de los entrevistados qué era transgenerismo. Esto llamó mi atención, pues puso en evidencia el desconocimiento del tema.

10. Es interesante pensar que el término "galleta” es cercano a “roscón”, términos que Eve Elster en los "Monólogos de la vagina” utiliza para retratar la injuria contra este órgano femenino con la comparación con "panocha”, "arepa”, “pan”, y demás productos de repostería. Este tipo de expresiones conectan lo cultural con lo literario. 
mente sin cuestionar el poder hiriente de las mismas. Los entrevistados dijeron también que no es inusual escuchar palabras peyorativas hacia las sexualidades no normativas en los corredores, zonas deportivas y salones de los colegios, aunque ellos (por temor o por vergüenza), hayan preferido no dar mayores detalles.

Vemos que el espacio escolar para un o una estudiante LGBTQ, como también para el resto de la comunidad educativa, es un espacio en el que se aprende a despreciar a quien no aparenta una orientación sexual heteronormativa. Esta situación nos hace pensar que la sexualidad entonces no es únicamente privada. Tiene efectos públicos, y entonces, como argumenta Halberstam (2005), es claro que lo que genera pánico social no es el acto sexual homosexual en sí, sino lo que Foucault ha llamado "el estilo de vida homosexual". ${ }^{11}$

En el trabajo de campo realizado también pudo verificarse que, pese a las diferentes formas en las que los jóvenes se apropian de los significados culturales, la sigla LGBTQ es poco conocida, y la información sobre diversidad sexual que los jóvenes manejan ha sido obtenida, en su mayoría, de la televisión, de las redes sociales y de sus compañeros.

En ninguno de los colegios visitados los jóvenes entrevistados expresaron que sus profesores les enseñaran sobre diversidad sexual, y mucho menos sobre el significado de la sigla LGBTQ. El tema sigue siendo tabú, y la educación sexual permanece enfocada en prevención de Enfermedades de Transmisión Sexual (ETS) y de embarazos no deseados.

Ante tal panorama surge una inquietud: aunque el tratamiento de la diversidad sexual no sea explícito, ¿suministran los colegios conocimientos que contribuyan a la construcción de una ciudadanía plena para los jóvenes LGBTQ? Además, como tal labor educativa es propia de la formación en humanidades que se recibe en secundaria, se indagó por la literatura que leen -o que han leído- los jóvenes durante sus años en la escuela. Efectivamente, se pudo comprobar que en los currículos no se incluyen textos de literatura homosexual, lo cual, aunque constituye una obviedad, visibiliza las carencias del sistema educativo para trabajar sobre una realidad tan cercana los jóvenes como la diversidad sexual. ${ }^{12}$

El lenguaje ofensivo sigue circulando, se reitera a diario, y el mensaje que transmite, incluso antes de que haya autoconciencia de lo que significa ser LGBTQ, es que los sentimientos y los "modos de vida" que de allí surgen son abyectos. Podríamos

11. If we try to think about queerness as an outcome of strange temporalities, imaginative life schedules, and eccentric economic practices, we detach queerness from sexual identity and come closer to understanding Foucault's comment in "Friendship as a Way of Life", that "homosexuality threatens people as a 'way of life' rather than as a way of having sex" (Halberstam, 2005: 1).

12. Dentro de los textos literarios que los jóvenes más han leído están: María de Jorge Isaacs; Pedro Páramo de Juan Rulfo; Cien Años de Soledad de Gabriel García Márquez; el Poema de Mio Cid; el Popol Vuh y Martin Fierro de José Hernández. Si bien puede entenderse el privilegio que son obras canónicas, dada la importancia de la literatura en la consolidación de una cultura nacional y regional, muchas otras narrativas podrían utilizarse para complejizar los estudios sobre historia y literatura. 
afirmar que la autoimagen de una persona con inclinación sexual no heterosexual es (incluso antes de que empiece a vivir su sexualidad) negativa, puesto que "mediante el lenguaje, y especialmente mediante la injuria, se aprende que se forma parte de una -o de varias- de las categorías inferiores" (Eribon, 2000: 57 ).

Las personas gays, lésbicas, bisexuales o transgénero tienen escasas posibilidades de ser consideradas positivas y de ser valoradas, pues el lenguaje ha consolidado un claro mensaje de odio que precede la entrada al mundo educativo. ¿Qué consecuencias acarrea el descubrimiento de la sexualidad como si se fuera el único en el mundo? Lo que el individuo siente tiene gran valor personal, pero es claro que socialmente no hay espacio para valorar los sentimientos de los jóvenes LGBTQ, o no al menos de la misma forma como se valoran los sentimientos de los jóvenes heterosexuales.

En los corredores de los colegios se escucha hablar de los "maricas", los "afeminados" y las "marimachas"; el odio que conlleva el desprecio hacia esos otros estudiantes de "menor categoría" se sedimenta, paulatinamente, en el corazón de la conciencia social con esas expresiones, y empieza a arraigarse para deslegitimar a toda una comunidad.

El lenguaje heteronormativo y homofóbico es mucho más lesivo de lo que imaginamos y, aunque varía según los contextos y las costumbres regionales, lo cierto es que transmite una contagiosa agresividad, como quizás históricamente también lo ha hecho el lenguaje dirigido a los afrodescendientes, los indígenas y las mujeres. Vale la pena preguntarnos ¿cómo modificar la forma en que nombramos a los otros? La forma en la que nombremos a los seres humanos les otorga una posición social, que en el caso de las personas LGBTQ los inferioriza. ¿Qué consecuencia trae consigo reducir a un ser humano a categorías como "marica" "cacorro" o "arepera"?13

Los humanos nos distinguimos de otras especies vivas por el lenguaje. Gracias a esta herramienta nos conectamos con los otros, construimos nuestra identidad e intervenimos la realidad conceptualizándola, narrándola y poetizándola. El lenguaje nos permite expresar nuestros razonamientos y también distinguirnos de los demás sentando nuestro criterio; por eso, en últimas, es la verbalización la que hace del mundo un mundo humano o inhumano. Pero ¿qué pasa cuando esa útil herramienta que me permite ser y existir en el mundo se voltea contra mí y, en vez de brindarme las posibilidades para hallar un lugar en el mundo humano, me dice diariamente que soy despreciable, abyecto o repugnante?

Al ser llamado con un nombre insultante, uno es menospreciado y degradado. Pero el nombre ofrece también otra posibilidad: al ser llamado por un nombre se le ofrece a uno también, paradójicamente, una cierta posibilidad de existencia social, se le inicia a uno en la vida temporal del lenguaje, una vida que excede los propósitos previos que animaban ese nombre (Butler, 1997: 17).

13. Términos utilizados también por los estudiantes entrevistados. 
He aquí otra invitación a reflexionar por qué resulta tan doloroso para el sujeto LGBTQ que la vida social le otorgue un nivel degradante. El mensaje de odio transmitido por el lenguaje da cuenta del nivel de desprecio existente hacia cierto grupo humano y por ello, aunque las palabras ofensivas sean tan comunes, están advirtiendo sobre la presencia de sujetos indeseables y susceptibles de ser denigrados. ¿Por qué no existen palabras ofensivas contra el modelo de hombre hegemónico, heterosexual, blanco y adinerado? Precisamente porque el imaginario social que se tiene sobre estos estereotipos hace que se aprecie cierta clase de personas y se desprecien a otras.

Lo que la injuria me dice es que soy alguien anormal o inferior, alguien sobre el que el otro tiene el poder, y, en principio, el poder de injuriarme. La injuria es, pues, la expresión de la asimetría entre los individuos, entre los que son legítimos y los que no lo son, y por la misma razón, son vulnerables. Lo cual quiere decir que la injuria es también mucho más que eso. Tiene también la forma de un poder constituyente, pues [...] la personalidad está moldeada por la misma existencia de esta jerarquía (Eribon, 2000: 55).

Ciertamente angustia pensar que no duele el daño causado a seres humanos en razón de su orientación sexual y, todavía más, saber que las condiciones para su exclusión están dadas y se apoyan en los referentes culturales desde los que se les nombra.

\section{Pensar los discursos dominantes sobre la sexualidad en la literatura juvenil}

El 30 de Noviembre de 2011 la Corte Constitucional de Colombia promulgó la sentencia T-905, que analizó la vulneración de los derechos fundamentales de una niña que era víctima, en su colegio, de lo que el alto Tribunal denominó matoneo ${ }^{14}$, propinado por sus compañeros de clase (todos ellos menores de 14 años). La razón por la cual esta niña era violentada, física y verbalmente, eran sus fuertes problemas de acné; ante la incompetencia de las directivas del establecimiento educativo, los padres de la menor decidieron interponer una acción judicial con el fin de proteger a su hija y evitar, a futuro, daños psicológicos irremediables.

Dado que el daño causado a la menor ya estaba consumado, poco o nada pudo hacer la Corte en su situación concreta ${ }^{15}$; pero sí resulta muy interesante que en esta sentencia,

14. Llama la utilización de este término por parte de un Alto Tribunal, pues el matoneo ha sido un concepto especialmente trabajado por psicólogos y trabajadores sociales. Al judicializarlo, el matoneo adquiere gran potencial para denominar, jurídica y políticamente, esta grave problemática social.

15. Técnicamente la Corte declaró una carencia actual de objeto por daño consumado. (Cfr. T-905-11) 
por primera vez, se obliga al Ministerio de Educación Nacional a poner en marcha una política pública de prevención, detención y atención a las prácticas de hostigamiento, acoso o matoneo escolar.

Aunque existen algunas acciones del Ministerio de Educación colombiano para diseñar esta política ${ }^{16}$, mi inquietud se ubica en el lugar que ocuparán en el diseño de dicha política los jóvenes LGBTQ (o aparentemente LGBTQ). ${ }^{17}$ ¿Qué importancia va a dar el Ministerio a la inclusión de una perspectiva sensible a quienes se perciben (o son percibidos) como LGBTQ? ¿Tendrán su propio "lugar de enunciación” los jóvenes LGBTQ en una política que, seguramente, va a tener hondas repercusiones en sus vida cotidianas? Y lo más importante: ¿es la sigla LGBTQ tan útil para lograr cambios en las vidas de jóvenes usuarios del sistema escolar como lo es para la obtención de derechos de parejas de adultos que deciden convivir juntos?

Más allá de alimentar posturas polarizadas (optimistas o pesimistas) sobre el futuro de los jóvenes no heterosexuales en Colombia, quiero terminar volviendo a poner de presente la importancia transversal de la literatura juvenil para avanzar en la educación sentimental de los jóvenes: de los maltratadores, de los maltratados y de los indiferentes.

\section{¿Es posible expandir los márgenes del orden simbólico heterocentrado desde el artefacto literario?}

Ahora, más que nunca en la historia de la educación, es fundamental subrayar la especial trascendencia que la literatura queer tendría en la discusión de políticas públicas de educación antibullying como las que se están discutiendo en Colombia. Intuyo que, frente a un tema tan sensible y crucial como la educación de jóvenes y adolescentes, la literatura tiene enorme potencial para derribar estereotipos, esencialismos y prejuicios; dicho potencial debe considerarse para el futuro del activismo social, de la interpelación al Estado y de la investigación en educación.

Fundamento mi posición en dos propuestas teóricas. En primer lugar, en la tesis desarrollada por el filósofo pragmatista Richard Rorty, según el cual gracias a que en

\footnotetext{
16. Para cumplir el fallo, el Ministerio de Educación ha diseñado unas guías borrador sobre "Convivencia en la escuela”, que pueden ser consultadas en línea y están abiertas a discusión pública: http://www.mineducacion.gov. co/1621/w3-article-322244.html [03/o9/2015]. Sería importante empezar otorgando mayor especificidad al acoso escolar contra personas LGBTQ, pues aunque se nombra la orientación sexual como un motivo de discriminación, no se profundizan todas sus particularidades.

17. El homicidio de dos hermanos en Brasil porque fueron percibidos como homosexuales mientras estaban expresándose afecto filial, dejó claro que la violencia generada en una cultura heteronormativa cobra la vida de inocentes incluso cuando intentan retar, así sea ilusoriamente, las identidades de género hegemónicas.

[Cfr. http://www.oas.org/es/cidh/prensa/comunicados/2012/o84.asp 12/o7/2012]
} 
la literatura encontramos historias tristes y sentimentales, es posible movilizar los sentimientos morales (culpa, indignación y resentimiento): los sentimientos que permiten el reconocimiento social (o la negación) del otro. Rorty argumenta que la importancia ética de las narraciones literarias radica en que logran cerrar las brechas que distancian a los seres humanos, al permitirles identificarse, en tanto humanos, más próximos de lo que la raza, la nacionalidad o la orientación sexual los diferencia (Rorty, 2000: 222).

Por su lado Eve Sedgwick (2003) señala la importancia de hacer lecturas reparativas (reparative reading) de los relatos existentes sobre las personas no heterosexuales, con las cuales se subviertan las lecturas paranoicas que usualmente se han hecho y que predominan. En otras palabras, si el orden simbólico se ha establecido generando pánico hacia las historias que surgen de las vidas de las personas homosexuales, las miradas reparativas a estas historias es crucial para hacer más sostenibles sus vidas en la teatralidad del mundo social (Hanson, 2011: 102).

Al igual que lo han afirmado varios trabajos previos (Cantor, 2008), en la actualidad la violencia simbólica, lingüística y física a la que están expuestos los jóvenes no heterosexuales en el sistema escolar colombiano es inmensa. Dicha violencia se mantiene, en gran medida, por las relaciones de poder y la estructura jerárquica que prima en la mayor parte de entornos educativos, y la respuesta del sistema escolar para desestimularla es insuficiente.

\section{Historias de amor que los jóvenes LGBTQ podrían leer}

Pensando en el catálogo de textos literarios queer colombianos a los cuales podrían acercarse los jóvenes, encontramos un amplio repertorio, dentro del cual es posible citar autores del siglo XIX como Porfirio Barba Jacob, y otros más contemporáneos como Raúl Gómez Jattin, Ana María Reyes, Fernando Vallejo y Alonso Sánchez Baute.

No obstante encontré algo especialmente atractivo en la obra de Fernando Molano Vargas: su obra más conocida, Un Beso de Dick (1992), bien podría clasificarse como literatura juvenil, puesto que narra una historia de amor de dos adolescentes, futbolistas y colegiales. Dos jóvenes con los cuales podría identificarse fácilmente cualquier estudiante de secundaria en Bogotá. Por ello, dada la centralidad que tiene el mundo escolar en la obra de Molano, la considero de especial relevancia para pensar el problema aquí planteado.

Al profundizar un poco en el estudio de la obra de Molano encuentro que Un Beso de Dick no es la única obra que retrata experiencias de vida de adolescentes homosexuales. El esfuerzo de este autor por registrar los códigos culturales juveniles de las décadas de los 80 y 90 es constante en su producción literaria. Vista desde una acera (1996), la novela autobiográfica que culminó un año antes de su muerte, también se desarrolla 
en un entorno juvenil. Allí Molano narra historias con un lenguaje sencillo y de fácil acceso, con una fuerte carga emotiva que bien puede confrontar los prejuicios de cualquier adolescente, y que también podría hacer inteligibles los afectos de un estudiante homosexual.

El siguiente párrafo presenta una breve historia que Molano vivió en su colegio, cuando cursaba primero de primaria y tenía cinco años de edad. Hallo en este tipo de historias no sólo gran valor literario sino también ético, ya que puede servir para avanzar en una educación reconocedora de las sexualidades no hegemónicas en la escuela:

\begin{abstract}
Ah, claro que yo amaba a ese niño; pero entonces a mí todavía no me habían dado las palabras: aquello no se llamaba "amor", su nombre sólo era "estar pensando siempre en él”. Hacía mucho tiempo sabía yo lo que sentía, pero no necesitaba conocer los nombres para saber que si los demás se enteraban, me hubieran dado una buena trilla. De alguna manera ya los mayores me habían enseñado que mi corazón estaba en la picota; no es difícil aprenderlo: jamás vi en los dibujos de mis libros de cuentos, ni en los de mi Cartilla Charry, ni en mi televisor, a un niño enamorado de otro niño. Así que nunca pude contarle a alguien lo mucho que extrañé para siempre a Miguel desde ese día de la clausura (Molano, 2012: 46) [Cursiva mía].
\end{abstract}

Llama la atención la manera en la que el Molano siendo niño empieza a descubrir el afecto homosexual sin saber cómo nombrarlo. Por ejemplo, al no recurrir a categorías (posteriormente impuestas y trasplantadas desde contextos anglófonos) como "gay", él logra expresar sus afectos utilizando el lenguaje urbano disponible, sin vocación política, propio de un menor de clase medio baja como a la cual él perteneció.

En este punto quiero detenerme para analizar el manejo literario que Molano hace de la figura del niño. Eve Sedgwick ha señalado que, mientras el niño simboliza en la cultura el futuro de la sociedad, el niño queer (como si ninguno de ellos existiera jamás) simboliza el riesgo del futuro que reprueba esa misma sociedad. El niño es el sujeto más "puro" que existe en la cultura dominante, el símbolo de la reproducción sexual y de la heteronormatividad, el "sujeto que garantiza que la heterosexualidad será la única alternativa posible" (Cornejo, 2011:142). En esa medida sobre el niño pesa el "futurismo reproductivo" que el orden simbólico necesita para mantenerse (Lee Edelman, citado por Cornejo: 142). En defensa de dicho futuro se justifica la violencia y el asesinato del niño queer: de su aniquilación depende la perpetuación social.

Al describir a un niño con afectos homosexuales, Molano logra darle al niño queer una mirada solidaria que hará posible su vida, su ser y sus afectos: subvierte con ello la univocidad del futuro heteronormativo establecido por la sociedad patriarcal. Miradas solidarias como estas son clave para los teóricos del giro afectivo de la teoría queer (Cornejo, 2011:149-150), y tienen enorme potencial para la educación de los jóvenes, porque 
les permite hallar coincidencias y similitudes en las formas en las que se despliegan los afectos humanos, prescindiendo de la orientación sexual.

Por otro lado, el niño Molano empieza a percibir que puede ser violentado ("trillado") por lo que siente, y aclara: "sin conocer los nombres" que recibe esa violencia. Lo anterior da cuenta de que las formas culturales en las que se construye la violencia contra hombres homosexuales es constante e irracional, y hace parte de la construcción de la identidad masculina hegemónica. Esto me hace pensar que en el contexto juvenil, usualmente distanciado de las grandes teorizaciones políticas, el formalismo del lenguaje de los derechos surgido de las actuales luchas LGBTQ, difícilmente logra contrarrestar la violencia contra los jóvenes no heterosexuales en sus escuelas.

En otro fragmento de Vista desde una acera, Molano presenta la lectura queer de uno de los autores que más influyó su poética, y uno de los escritores más apetecidos por el público juvenil: Charles Dickens. Esta "mirada alternativa" de Dickens que construye Molano me inquieta, no sólo por lo inspiradora que fue para el colombiano, sino porque implica retar la narrativa convencional que se ha hecho del escritor inglés. En el siguiente párrafo, el joven adolescente Fernando Molano explica por qué la interpretación homosexual que él hizo del clásico Oliver Twist tuvo tanta trascendencia en su vida. Tras evocar eróticamente la imagen de Mark Lester (el niño que protagonizó la película basada en el libro, y que él siempre quiso ver), Molano nos cuenta:

Mark Lester fue mi niño imposible más bello de este mundo. Pero fue Oliver, o Mark Lester vestido de Oliver, por quien esa noche me hice el propósito de leer el libro como fuera, así tardara mil años intentando comprender todas las palabras [...]

No sé si fue porque traía mucho impulso de las ganas de leerlo, o por qué, pero el caso es que fui pasando de una página a otra como se pasa de un tobogán al columpio y del columpio al balancín y del balancín a la rueda loca, y todo así: como si nada. Pero cuando llegue al final del capítulo VII, quedé congelado sobre la página. Casi no lo creía: allí Oliver se dio un beso con otro niño, con su mejor amigo, Dick. Y se abrazaron.

Supongo que nadie recordará esa escena. Al menos, no como la recuerdo yo. Porque, claro, sólo yo tengo mi corazón. Y supongo que si alguien la leyó, sólo habrá visto a dos niños diciéndose adiós; Oliver porque se iba a Londres, Dick porque se iba a morir, y lo sabía. Yo vi otra cosa: dos niños que se besaban; dos niños que se querían. (Molano, 2012: 92-93) (Cursiva mía, que uso para resaltar el fragmento que da título a este trabajo).

La inclusión de esta novela en un currículo de educación para adolescentes sería valiosa en una política pública anti matoneo que pretenda avanzar en la erradicación de la violencia contra los jóvenes LGBTQ. Este tipo de historias literarias permitirían descubrir, siguiendo a Rorty, a los jóvenes LGBTQ como seres de afecto digno de ser reconocido. 
Fernando Molano vivió y escribió en una de las épocas más difíciles de la historia colombiana: finales de la década de los 80 y principios de los 9o, cuando la declarada guerra de los narcotraficantes contra el Estado colombiano amenazaba con sumir al país en una espiral interminable de violencia. Pero también vivió el surgimiento de un movimiento de jóvenes ${ }^{18}$ que, cansados de la agudización de la crisis social, lucharon por transformar la realidad e incentivaron la promulgación de la Constitución de 1991 (marco normativo vigente, dentro del cual ha ganado todos sus derechos la comunidad LGBTQ). Quizás la mezcla de desilusión y optimismo que atravesó Colombia a principios de los 90 se refleja también en la producción literaria de Fernando Molano. Por ello su obra puede servir a todos los jóvenes queer que, como él, aún hoy sueñan sus vidas posibles en medio de las violencias que padecen. En las espaldas de los niños y jóvenes queer recae el peso de las lecturas paranoicas que se han hecho de las historias de amor entre niños o adolescentes fuera de los marcos culturales convencionales.

\section{Conclusión}

No se puede hablar de la homosexualidad si no se habla de la homofobia, ya que no se puede decir nada de la realidad -individual, social, cultural, jurídica- de la homosexualidad si no se toma en cuenta el sistema homófobo que es constitutivo de esta realidad (Eribon, 2000:58).

Con estas palabras Eribon invita a que ninguna reflexión sobre la diversidad sexual ignore el panorama discursivo en el que está envuelta. Ser LGBTQ en Colombia, como en cualquier país en donde históricamente predomine la heterosexualidad obligatoria, es saber qué es ser injuriado, ofendido e insultado. Además, ser estudiante LGBTQ es saber que, probablemente, en la escuela no habrá espacio para sus afectos: ni en las clases que recibe, ni en las preguntas que hace ni con las personas con las que comparte su vida; no de forma plena, no al menos sin llamar la atención.

Eribon no está diciendo que el lenguaje ofensivo englobe el problema, ni que sea el único mal a atacar. Por el contrario, como hemos visto, la superación de un sistema ideológico homo-transfóbico violento es el proyecto que hay que continuar, sabiendo que uno de sus pilares es la economía discursiva que opera tras él. Pero ante el predominio de un lenguaje de odio que se ha sedimentado históricamente, invito a oponer un lenguaje reparador como el que encontramos en los relatos literarios y en la poesía. Es importante quebrar la citacionalidad del lenguaje de odio, e introducir en cada quiebre expresiones poéticas que posibilitan otras comprensiones, y que otorgan la posibilidad 
de dignificar vidas. Mi intento no ha sido suplantar un paradigma discursivo ideológico por otro. Más bien, he buscado articular un encuentro entre discursos ofensivos y discursos alentadores, y pensar en la importancia de multiplicar lenguajes al hablar de sexualidad en la escuela. Estimo importante dejar de privilegiar el binario lenguaje de los derechos y los deberes, y entender que para desplazar ciertas estructuras discursivas necesitamos abrir los horizontes de enunciación en múltiples direcciones.

Algunas de las propuestas de educación en diversidad sexual que se han puesto en marcha en Colombia han recibido duras críticas, no sólo por los sectores sociales más conservadores, sino por importantes funcionarios del Estado. Incluso el debate se ha politizado, al punto que líderes políticos se oponen acérrimamente a que en Bogotá se enseñe a los jóvenes, en sus colegios, el respeto y la valoración de sus compañeros homosexuales. ${ }^{19}$ En medio de esta turbulencia el Ministerio de Educación recibe la orden de la Corte Constitucional para diseñar una política pública anti matoneo, y si los jóvenes queer son una de las poblaciones más golpeadas por el matoneo en la escuela ¿qué acciones se están emprendiendo para afrontar las particularidades que reviste el acoso escolar en razón de la orientación sexual o la identidad de género?

El lenguaje de los derechos, pese a ser una conquista importante de nuestra civilización, difícilmente logra movilizar los sentimientos morales que otorgan reconocimiento ético al otro. Implantar cátedras a un público juvenil para instruir en derechos LGBTQ (realidades que pueden parecer etéreas para la cotidianidad adolescente) no logra generar lecturas reparadoras de los prejuicios, miedos y paranoias culturales que recaen sobre las vidas de personas sexualmente diversas. Las lecturas reparadoras requieren movilizar el sentimiento a través de relatos cercanos a las experiencias cotidianas de los jóvenes, como los que se encuentra en la literatura, o en otras expresiones artísticas como el cine.

Aunque en Bogotá existen algunos colectivos de jóvenes LGBTQ, en amplias zonas de la ciudad y en la mayoría del país los debates sobre la diversidad sexual aún se encuentran censurados. En ese sentido, los discursos que provienen del movimiento LGBTQ difícilmente penetran los muros de los planteles educativos (privados o públicos), y si lo hacen, no dejan de levantar polémica. Para avanzar en esta área, desde las literaturas juveniles puede empezar a abonarse el terreno para pensar políticas de educación incluyentes y valoradoras de la diversidad. Así, miles de jóvenes que empiezan a descubrir su sexualidad en completa soledad y aislamiento podrán encontrar en lecturas que describen vidas tan solitarias y aisladas, como la de Fernando Molano, una mirada solidaria para sus innombradas maneras de descubrimiento afectivo.

19. Clara Lucía Sandoval, concejal de Bogotá por el partido político más fuerte en Colombia (el partido de la U), a principios del año 2012, inició una batalla jurídica contra la Secretaría de Educación de la ciudad por considerar que, al implementar clases sobre comunidad LGBTI, se promovía la homosexualidad y se perturbaba la educación de los jóvenes. (El Tiempo, 2012). 


\section{Postscriptum}

A pocos días de la publicación del presente ensayo me enteré del lamentable fallecimiento del profesor Andrés Felipe Castelar Caicedo (Q.E.P.D). Andrés fue un distinguido colega, que leyó versiones anteriores de este texto, y que aportó importantes comentarios que he incorporado a la versión final. Compartimos discusiones muy productivas, especialmente sobre Judith Butler, pues ambos hicimos nuestras tesis de maestría en filosofía sobre el pensamiento de esta teórica. Quiero dedicar este trabajo a su memoria, pues él fue una persona fundamental para la construcción de muchos de los argumentos que he desarrollado aquí. Igualmente, espero que estas páginas también sirvan para recordar a este gran amigo, y hacer duelo por su triste e irremplazable pérdida.

\section{Referencias}

BUTLER, J. (2007). El Género en Disputa. Barcelona: Paidós. . (1997). Lenguaje, poder e identidad. Madrid: Síntesis.

CANTOR, E. (2008). Homofobia y Convivencia Escolar. Bogotá, Colombia: Universidad Pedagógica Nacional.

CORNEJO, G. (2011). “Contra la familia: ¿Cómo hacer justicia a los niños afeminados?” Nómadas (35). Bogotá, Colombia: Universidad Central.

CONSEJO DE ESTADO. Sentencia de 12 de Noviembre de 2014, Impugnación de Acción de Tutela. República de Colombia.

EL ESPECTADOR. (2008). Nuevas protestas en colegio de Manizales por dos niñas lesbianas. 28 de Abril de 2008.

EL TIEMPO. (2012). 28 de Enero. Según concejal, dar clases sobre la comunidad LGBT podría estar promoviendo la homosexualidad. 29 de Enero de 2012.

. Dos estudiantes lesbianas que habian sido expulsadas de un colegio de Manizales serán reintegradas. 24 de Abril de 2008.

ERIBON, D. (2000). Identidades, reflexiones sobre la cuestión gay. Barcelona: Ediciones Bellaterra.

FELMAN, S. (2002). The Juridical Unconscious: Trials and Traumas in the Twentieth Century. Harvard: University Press.

HALBERSTAM, J. (2005). In a Queer Time and Place: Transgender Bodies, Subcultural Lives. NY: New York University Press. 
HANSON, E. (2011). The Future's Eve: Reparative Reading after Sedgwick”. The South Atlantic Quarterly, 110 (1), 101-119.

LEMAITRE RIPOLL, J. (2009). El derecho como conjuro: fetichismo legal, violencia y movimientos sociales. Bogotá, Colombia: Siglo del Hombre y Universidad de Los Andes.

MOLANO VARGAS, F. (1992). Un Beso de Dick. Medellín, Colombia: Cámara de Comercio. . (2012). Vista desde una acera. Bogotá: Seix Barral. . (1997). Todas mis cosas en tus bolsillos. Universidad de Antioquia, Colombia: Celeste.

REPÚBLICA DE COLOMBIA. (2011). Corte Constitucional. Sentencia T-905

RORTY, R. (2000). “Derechos Humanos, racionalidad y sentimentalismo”, en: Verdady progreso. Barcelona: Paidós.

SEDGWICK, E. (2003). "Paranoid Reading and Reparative Reading, or, You're So Paranoid, You Probably Think This Essay Is about You”, en: Touching Feeling: Affect, Pedagogy, Performativiy. Duke University Press.

\section{Fuentes online}

And This is Jamey's HAUSE. (2011, 4 de Mayo). “It Gets Better, I promise!”. Youtube [archivo de video] Recuperado de: https://www.youtube.com/watch?v=-PbiCaGMdWk 